\title{
Development of a Rapid Diagnostic Kit for Congestive Heart Failure Using Recombinant NT-proBNP Antigen
}

\author{
Young-Ki Lee ${ }^{1}$, Dong-Ok Choi ${ }^{2}$ and Ga-Yeon Kim ${ }^{3, *}$ (D) \\ 1 Department of Biomedical Laboratory Science, College of Health Sciences, Dankook University, 119 \\ Dandae-ro, Dongnan-gu, Cheonan-si 31116, Chungnam, Korea; pp99pp@dankook.ac.kr \\ 2 Bore Da BioTECH Co., LTD., 14, B-505, Sagimakgol-ro 45 beon-gil, Jungwon-gu, \\ Seongnam-si 13209, Gyeonggi-do, Korea; realchoi@boreda.com \\ 3 Department of Public Health, Graduate School, Dankook University, 119 Dandae-ro, Dongnan-gu, \\ Cheonan-si 31116, Chungnam, Korea \\ * Correspondence: sysnhj77@gmail.com; Tel.: +82-41-550-1493; Fax: +82-41-550-1490
}

\section{check for}

updates

Citation: Lee, Y.-K.; Choi, D.-O.; Kim, G.-Y. Development of a Rapid Diagnostic Kit for Congestive Heart Failure Using Recombinant NT-proBNP Antigen. Medicina 2021, 57, 751. https://doi.org/ 10.3390/medicina57080751

\section{Academic Editors:}

Anton Sabashnikov,

Aron-Frederik Popov and Ignatios Ikonomidis

Received: 17 May 2021

Accepted: 22 July 2021

Published: 25 July 2021

Publisher's Note: MDPI stays neutral with regard to jurisdictional claims in published maps and institutional affiliations.

Copyright: (c) 2021 by the authors. Licensee MDPI, Basel, Switzerland. This article is an open access article distributed under the terms and conditions of the Creative Commons Attribution (CC BY) license (https:/ / creativecommons.org/licenses/by/ $4.0 /)$.

\begin{abstract}
Background and Objectives: In patients with congestive heart failure, brain natriuretic peptide (BNP) and N-terminal prohormone of brain natriuretic peptide (NT-proBNP) are released due to excessive heart muscle expansion; they can be used for the early detection, progress monitoring, and treatment of congestive heart failure. Recently, considerable efforts have been made to develop an NT-proBNP-based biomarker for detecting heart failure. This study attempts to develop a rapid and accurate congestive heart failure diagnostic kit using NT-proBNP. Materials and Methods: A new gene based on NT-proBNP was selected, recombined, and expressed in Escherichia coli strains, and then monoclonal antibodies were produced using the hybridoma technique. Additionally, antigen-antibody reactivity was confirmed using indirect enzyme-linked immunosorbent assay (ELISA). Furthermore, the first pair and full-strip pair tests were conducted to select candidate clones; these were applied to a rapid diagnosis kit based on gold conjugates and compared with other currently available antigens. Results: NT-proBNP-based antigens with high specificity and monoclonal antibodies were produced, and the optimal antigen-antibody reactivity was confirmed using indirect ELISA. The first pair and full-strip pair tests were performed to select the optimal candidate clones, and a rapid diagnosis kit with excellent reactivity was developed by applying these to a rapid diagnosis kit based on gold conjugates. Conclusions: The development of this rapid diagnosis kit with excellent performance in congestive heart failure is expected to improve disease management by providing an early assessment of the risk of heart failure.
\end{abstract}

Keywords: BNP; congestive heart failure; NT-proBNP; rapid diagnostic kit; biomarker

\section{Introduction}

Congestive heart failure (CHF) is associated with high morbidity and mortality worldwide. Hence, early detection and treatment of this disease are of importance. Recently, considerable efforts, including clinical level studies, have been made to develop biomarkers for heart failure (HF) [1,2]. Types of biomarkers for measuring heart failure disease using peripheral blood include $\mathrm{HF}$ inflammation biomarkers ( $\mathrm{C}$ reactive protein $(\mathrm{CRP})$ and interleukin 6 (IL-6), HF myocyte injury biomarkers (cardiac-specific troponin I (CTnI), and creatine kinase-MB (CK-MB), and HF myocyte stress biomarkers (B-type natriuretic peptide (BNP) and ST2 proteins). Among them, BNP and ST2 proteins, which are myocardial stress peptide biomarkers, accurately reflect the worsening prognosis of HF patients. In particular, BNP is a strong prognostic factor for all causes of death in asymptomatic patients and heart failure patients at all disease stages [3]. The mechanism underlying the association between BNP and HF involves the downregulation of the renin-angiotensin-aldosterone system by BNP, which reduces the sympathetic nerve activity of the heart and kidneys. It increases blood flow to the kidneys as well as sodium secretion by directly acting on renal 
collecting ducts [4]. Similar to BNP, N-terminal prohormone of brain natriuretic peptide (NT-proBNP), a proBNP derivative, is a new and important biomarker determining the severity of a heart attack $[5,6]$. This biomarker comprises 108 amino acids and is produced in ventricular muscle cells (Figure 1). It is split by endoprotease furin into the active C-terminal polypeptide BNP, consisting of 32 amino acids, and inactive NT-proBNP, comprising 76 amino acids [7]. The secretion of these two peptides is increased by ventricular wall expansion and volume overload, resulting in the release of both at the same rate. Also, due to its longer half-life, NT-proBNP shows higher sensitivity to early stages of left ventricular disorders. Thus, the detection of NT-proBNP may improve HF prognosis and facilitate the effective management of disease by providing an accurate risk assessment of HF $[8,9]$.

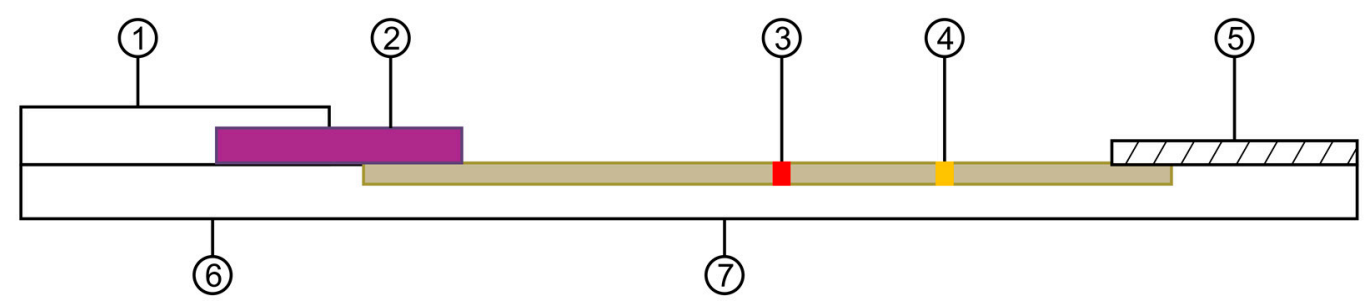

Figure 1. Structure of the rapid diagnosis kit. (1) sample pad; (2) conjugated pad; (3) test line; (4) control line; (5) absorbance pad; (6) plastic backbone; (7) nitrocellulose membrane.

Although various laboratory tests enabling early detection of HF are available, these traditional diagnostic methods do not ensure the efficacy, accuracy, timeliness, or costeffectiveness of clinical decisions, prognoses, and treatments. Thus, a new NT-proBNP biomarker-based test showing relatively high diagnostic and prognostic capabilities and clinical usefulness may fulfill the need for a rapid diagnostic method and point-of-care (POC) [10].

Cardiac resynchronization therapy (CRT) is highly effective for heart failure patients with type 2 diabetes mellitus, significantly improving clinical symptoms and reducing mortality and long-term morbidity [11,12]. A wide range of biomarkers can be used as predictors of the CRT response in heart failure patients receiving such treatments. BNT-proBNP, in particular, has high sensitivity and specificity, and there is a significant correlation between BNP levels and CRT results [13,14].

The objective of this study was to develop a rapid and accurate diagnostic kit for CHF, which can be applied in clinical practice by selecting and recombining a new gene based on NT-proBNP and expressing it in Escherichia coli. This process develops an antigen with high specificity that produces hybridomas and monoclonal antibodies while identifying optimal antigen-antibody reactivity via indirect enzyme-linked immunosorbent assay (ELISA). A first pair test was conducted to select candidate clones, followed by selecting an optimal pair via a full-strip pair test. This pair was applied to a diagnosis kit based on gold conjugates to develop a rapid diagnosis kit based on NT-proBNP with excellent reactivity compared with other commercially available antigens. The results of this study are expected to significantly contribute to the early diagnosis and treatment of related diseases by reducing test costs and improving conventional methods that require expensive equipment and specialists.

\section{Materials and Methods}

\subsection{NT-proBNP Gene Synthesis and Cloning}

This study began in February 2018 and ended in October 2020 after receiving accreditation for animal testing by ethics review. The human proBNP sequence, registered in the National Center for Biotechnology Information (NCBI), was used as a reference to select a single segment of the amino acid sequence predicted to target and identify the NT-proBNP region (Table 1). Primer and gene synthesis, which incorporate sites for the HindIII and XhoI restriction enzymes in the selected amino acid sequence, were performed 
by Bioneer (Bioneer, Daejeon, Korea). The newly synthesized NT-proBNP was transformed into E. coli DH5 $\alpha$ and incubated in LB broth (Sigma-Aldrich, Darmstadt, Germany) at $37^{\circ} \mathrm{C}$ for $15 \mathrm{~h}$. Plasmid DNA was extracted using a DNA extraction kit (Nucleogen, Seoul, Korea). Polymerase chain reaction (PCR) was performed using the extracted plasmid as a template. Primers containing a HindIII site in the forward region and an XhoI cleavage site in the reverse region (Table 2) were used to perform amplification under the following conditions: $94{ }^{\circ} \mathrm{C}$ for $30 \mathrm{~s}$ (denaturation), $53{ }^{\circ} \mathrm{C}$ for $30 \mathrm{~s}$ (annealing), and $72{ }^{\circ} \mathrm{C}$ for $30 \mathrm{~s}$ (extension). The entire process was repeated 37 times and allowed to react at $72{ }^{\circ} \mathrm{C}$ for 5 min in the post-extension period prior to completion. The PCR-amplified product was subjected to electrophoresis at $140 \mathrm{~V}$ on a $1.5 \%$ agarose gel for $20 \mathrm{~min}$ and stained with $0.5 \mathrm{mg} / \mathrm{L}$ of ethidium bromide (EtBr; $2 \%$ ) for $30 \mathrm{~min}$. The PCR products were observed using a Molecular Imager Gel DOC TM XR+ System (Bio-Rad, Irvine, CA, USA). Subsequently, the PCR-amplified product was eluted from agarose gel using a gel extraction kit (Nucleogen, Daejeon, Korea) for recombination. The recombinant mixture was prepared by adding $1 \mu \mathrm{L}$ of the purified PCR product, $4 \mu \mathrm{L}$ of distilled water, $1 \mu \mathrm{L}$ of buffer $\mathrm{A}, 1 \mu \mathrm{L}$ of buffer $\mathrm{B}$, $2 \mu \mathrm{L}$ of TA vector, and $1 \mu \mathrm{L}$ of TA ligase to produce a final volume of $10 \mu \mathrm{L}$, and reacted at $25{ }^{\circ} \mathrm{C}$ for $2 \mathrm{~h}$. The PCR product was recombined using a TA-cloning kit (Intron, USA). DNA transformation was achieved by combining the recombinant mixture with E. coli $\mathrm{DH} 5 \alpha$ (stored at $-80^{\circ} \mathrm{C}$ ) and stabilizing on ice for over $30 \mathrm{~min}$. Subsequently, a heat block was prepared at $42{ }^{\circ} \mathrm{C}$, and the preparation was subjected to heat shock for $1 \mathrm{~min}$ and $30 \mathrm{~s}$. The transformed cell solution was plated on LB solid medium and cultured at $37^{\circ} \mathrm{C}$ for $18 \mathrm{~h}$. A single colony was randomly selected, inoculated again in $6 \mathrm{~mL}$ of LB medium, and cultured at $37^{\circ} \mathrm{C}$ for $15 \mathrm{~h}$. DNA was extracted using a DNA extraction kit (Bioneer, Daejeon, Korea).

Table 1. NT-proBNP amino acid sequence.

\begin{tabular}{ll}
\hline Gene & Amino Acid Sequence \\
\hline & 001-HPLGSPGSASDLETSGLQEQRNHLQGKLSE \\
NT-proBNP & 031-LQVEQTSLEPLQESPRPTGVWKSREVATEG \\
& 061-IRGHRKMVLYTLRAPR \\
\hline
\end{tabular}

Table 2. PCR primer sequences for the amplification of NT-proBNP.

\begin{tabular}{lll}
\hline Gene & & Amino Acid Sequence \\
\hline \multirow{2}{*}{ NT-proBNP } & Forward & $5^{\prime}$ - AAG CTT CAC CCG CTG GGC AGC CCC-3' \\
\cline { 2 - 3 } & Reverse & $5^{\prime}$ - CTC GAG TCG TGG TGC CCG CAG GGT-3 ${ }^{\prime}$ \\
\hline
\end{tabular}

The forward and reverse primers contain HindIII (AAGCTT) and XhoI (CTCGAG) restriction sites.

\subsection{Expression Vector Subcloning}

In order to express the recombinant protein, subcloning was performed using the pET-21b vector (Novagen, Sigma-Aldrich, Darmstadt, Germany). After combining the expression vector and purified target inserts at a molar ratio of 1:3, $0.5 \mu \mathrm{L}$ of T4 ligase and $1 \mu \mathrm{L}$ of buffer were added to adjust the final volume to $10 \mu \mathrm{L}$ and reacted at $37^{\circ} \mathrm{C}$ for $1 \mathrm{~h}$. In order to identify colonies containing inserts and the TA vector, colonies were treated with HindIII and XhoI. Subsequently, a single colony was selected and cultured on LB solid medium at $37^{\circ} \mathrm{C}$ for $18 \mathrm{~h}$. It was then reinoculated in $6 \mathrm{~mL}$ of LB medium and cultured at $37^{\circ} \mathrm{C}$ for $15 \mathrm{~h}$. DNA was extracted using a DNA extraction kit. Extracted DNA was added to $1 \mu \mathrm{L}$ of enzyme buffer solution and $0.25 \mu \mathrm{L}$ in each of the restriction enzymes, HindIII and XhoI, to adjust the final volume to $10 \mu \mathrm{L}$, and reacted at $37^{\circ} \mathrm{C}$ for $1 \mathrm{~h}$. Subsequently, electrophoresis in a 1.5\% agarose gel was performed at $140 \mathrm{~V}$ for $20 \mathrm{~min}$, followed by staining with $\mathrm{EtBr}(0.5 \mathrm{mg} / \mathrm{L})$ for $30 \mathrm{~min}$ to identify the presence of the target fragment. Next, the confirmed DNA was transformed into E. coli BL21 (DE3) in the same manner as described above. 


\subsection{Recombinant Protein Expression and Purification}

For protein expression, the transformed E. coli BL21 (DE3) strain was inoculated into $10 \mathrm{~mL}$ of LB medium, followed by seed culture at $37^{\circ} \mathrm{C}$ for $15 \mathrm{~h}$. Subsequently, $5 \mathrm{~mL}$ of seed culture solution, which was $1 / 100$ of the final volume, was inoculated into $500 \mathrm{~mL}$ of LB medium, followed by incubation at $37^{\circ} \mathrm{C}$ for $2 \mathrm{~h}$. Following incubation, $0.25 \mathrm{mM}$ isopropyl $\beta$-D-1-thiogalactopyrano-side (Goldbio, St. Louis, MO, USA) was added until the absorbance at $600 \mathrm{~nm}$ reached $0.6-0.8$; afterward, protein expression was induced by shaking the culture at $180 \mathrm{rpm}$ for $15 \mathrm{~h}$ at $18{ }^{\circ} \mathrm{C}$ [15]. Protein-expressing cells were then centrifuged in a 250 -mL tube at $11,100 \times g, 4^{\circ} \mathrm{C}$ for $10 \mathrm{~min}$ to precipitate cells. Phosphatebuffered saline (PBS, pH 7.4) was mixed with $1 / 10$ of the culture volume solution and subjected to ultrasonic disintegration for $2 \mathrm{~min}$. The supernatant was then recovered via centrifugation under conditions similar to those described above.

Ni-NTA affinity chromatography was used to purify the expressed recombinant proteins [16]. PBS ( $\mathrm{pH} 7.4$ ) was used as the binding buffer, whereas imidazole solution (adjusted to a concentration of $30 \mathrm{mM}$ in PBS (pH 7.4) was used as the washing buffer; $250 \mathrm{mM}$ imidazole buffer was used for elution. In order to remove the high concentration of imidazole in the elution, $5 \mathrm{~L}$ of PBS ( $\mathrm{pH} 7.4$ ) was prepared and maintained at $4{ }^{\circ} \mathrm{C}$ for $20 \mathrm{~h}$ for dialysis. Sodium dodecyl sulfate-polyacrylamide gel electrophoresis (SDS-PAGE) was performed using a vertical Mini-PROTEAN Tetra cell device (Bio-Rad, Irvine, CA, USA) to identify the protein. With the expected protein size considered, the concentration of acrylamide in the running gel and stacking gel was set to $14 \%$ and $4 \%$, respectively. The size of the target protein was identified by Coomassie Blue staining (MilliporeSigma, Darmstadt, Germany) [17].

\subsection{Mouse Immunization and Cell Fusion}

Two 5-week-old (Balb/C) mice were immunized using the recombinant antigen. The experimental protocol was approved by the Institutional Animal Care and Use Review Committee of Bore Da BioTECH (BDIACUC20180221). After preparing the antigen at $1 \mathrm{mg} / \mathrm{mL}$, an emulsion was prepared by mixing with complete Freund's adjuvant (CFA; Sigma-Aldrich, Darmstadt, Germany) at a ratio of 1:1. The first immunization was performed on the sole of each mouse $(100 \mu \mathrm{L})$. The second immunization was performed two weeks after the first immunization and then weekly, starting with the third immunization. From the second immunization to the fourth and final immunization, $75 \mu \mathrm{L}$ was used. One week later, the mice were sacrificed by cervical dislocation, and the lymph nodes were removed. The extracted lymph nodes were fused with $\mathrm{Sp} 2 / \mathrm{O}$, a mouse myeloma cell line, using polyethylene glycol 1500 (Roche, Switzerland). To selectively culture the fused cells, hypoxanthine aminopterin thymidine (HAT, Sigma-Aldrich) medium was used. After preparing a 96-well plate and dispensing $200 \mu \mathrm{L}$ /well, each plate was incubated at $37^{\circ} \mathrm{C}$ in a $\mathrm{CO}_{2}$ incubator.

\subsection{Hybridoma Screening}

The cultured hybridomas were screened using an indirect ELISA. First, the recombinant antigen was dispensed into a 96-well plate at $50 \mu \mathrm{L} /$ well and reacted at $4{ }^{\circ} \mathrm{C}$ for $16 \mathrm{~h}$ or longer. After washing with phosphate-buffered saline-Tween20 (PBS-Tween20, Merck), $0.25 \%$ casein (Sigma-Aldrich) was dispensed at $100 \mu \mathrm{L} /$ well and reacted at $37^{\circ} \mathrm{C}$ for $1 \mathrm{~h}$ or longer to block sites where the antigen was not attached. After washing with PBS-Tween20 (Merck), hybridoma culture medium was dispensed at $100 \mu \mathrm{L} /$ well and incubated at $37^{\circ} \mathrm{C}$ for $1 \mathrm{~h}$. Samples were washed with PBS-Tween 20 before each reaction. Horseradish peroxidase-conjugated goat anti-mouse IgG (Invitrogen, Irvine, CA, USA), diluted 1:10,000, was dispensed at $100 \mu \mathrm{L} /$ well and incubated at $37^{\circ} \mathrm{C}$ for $1 \mathrm{~h}$. To detect the reaction, the color-developing substrate solution, 3,3',5,5'-tetramethylbenzidine (SigmaAldrich), was dispensed at $50 \mu \mathrm{L} /$ well to induce an enzymatic reaction. After reacting for $5 \mathrm{~min}, 1 \mathrm{~N} \mathrm{H}_{2} \mathrm{SO}_{4}$ was dispensed at $50 \mu \mathrm{L} /$ well to terminate the enzymatic reaction. In order to determine the degree of color development, absorbance was measured at $450 \mathrm{~nm}$ 
using a microplate reader (Biotek, Winnooski, VT, USA), and 11 fused cells showing high absorbance were selected (Table 3).

Table 3. Indirect ELISA for primary screening.

\begin{tabular}{|c|c|c|c|c|c|c|c|c|c|c|c|c|c|}
\hline \multirow{9}{*}{ Plate 1} & C1 & 1 & 2 & 3 & 4 & 5 & 6 & 7 & 8 & 9 & 10 & 11 & 12 \\
\hline & A & 0.422 & 0.472 & 0.303 & 0.353 & 0.3 & 0.411 & 0.289 & 0.338 & 0.335 & 0.258 & 0.292 & 0.398 \\
\hline & B & 0.281 & 0.274 & 0.313 & 0.304 & 0.247 & 0.76 & 0.263 & 0.275 & 0.284 & 0.275 & 0.258 & 0.295 \\
\hline & C & 0.288 & 0.233 & 0.72 & 0.263 & 0.249 & 0.3 & 0.287 & 0.259 & 0.267 & 0.287 & 0.261 & 0.283 \\
\hline & $\mathrm{D}$ & 0.348 & 0.26 & 0.29 & 0.265 & 0.287 & 0.263 & 0.258 & 0.277 & 0.585 & 0.222 & 0.693 & 0.303 \\
\hline & $\mathrm{E}$ & 0.31 & 0.254 & 0.684 & 1.043 & 0.265 & 0.289 & 0.279 & 0.479 & 0.232 & 0.242 & 0.237 & 0.308 \\
\hline & $\mathrm{F}$ & 0.37 & 0.225 & 0.268 & 0.272 & 0.305 & 0.451 & 0.275 & 0.302 & 0.307 & 0.267 & 0.294 & 0.278 \\
\hline & G & 0.355 & 0.276 & 1.197 & 0.334 & 0.325 & 0.231 & 0.251 & 0.287 & 0.292 & 0.253 & 0.274 & 0.308 \\
\hline & $\mathrm{H}$ & 0.325 & 0.333 & 0.337 & 0.303 & 0.366 & 0.347 & 0.27 & 0.308 & 0.264 & 0.279 & 0.282 & 0.833 \\
\hline \multirow{9}{*}{$\begin{array}{c}\text { Plate } \\
2\end{array}$} & C2 & 1 & 2 & 3 & 4 & 5 & 6 & 7 & 8 & 9 & 10 & 11 & 12 \\
\hline & A & 0.307 & 0.309 & 0.276 & 0.27 & 0.332 & 0.342 & 0.281 & 0.252 & 0.297 & 0.299 & 0.298 & 0.358 \\
\hline & B & 0.281 & 0.25 & 0.282 & 0.269 & 0.28 & 0.303 & 0.288 & 0.302 & 0.267 & 0.241 & 0.239 & 0.315 \\
\hline & C & 0.454 & 0.293 & 0.272 & 0.302 & 0.281 & 0.27 & 0.258 & 0.253 & 0.259 & 0.27 & 0.218 & 0.342 \\
\hline & $\mathrm{D}$ & 0.304 & 0.26 & 0.289 & 0.317 & 0.313 & 0.28 & 0.32 & 0.321 & 0.288 & 0.253 & 0.253 & 0.275 \\
\hline & $\mathrm{E}$ & 0.3 & 0.255 & 0.334 & 0.287 & 0.289 & 0.282 & 0.298 & 0.278 & 0.295 & 0.279 & 0.298 & 0.25 \\
\hline & $\mathrm{F}$ & 0.254 & 0.249 & 0.275 & 0.439 & 0.263 & 0.288 & 0.46 & 0.279 & 0.34 & 0.259 & 0.252 & 0.278 \\
\hline & G & 0.311 & 0.359 & 343 & 0.278 & 0.31 & 0.29 & 0.381 & 0.286 & 0.347 & 0.287 & 1.137 & 0.465 \\
\hline & $\mathrm{H}$ & 0.411 & 0.984 & 0.295 & 0.272 & 0.287 & 0.284 & 0.289 & 0.525 & 0.341 & 0.254 & 0.313 & 0.317 \\
\hline \multirow{9}{*}{$\begin{array}{c}\text { Plate } \\
3\end{array}$} & C3 & 1 & 2 & 3 & 4 & 5 & 6 & 7 & 8 & 9 & 10 & 11 & 12 \\
\hline & A & 0.497 & 0.384 & 0.444 & 0.375 & 0.447 & 0.399 & 0.353 & 0.477 & 0.43 & 0.41 & 0.48 & 0.661 \\
\hline & B & 0.364 & 0.371 & 0.356 & 0.364 & 0.368 & 0.312 & 0.339 & 0.378 & 0.369 & 0.385 & 0.934 & 0.41 \\
\hline & C & 0.442 & 0.409 & 0.38 & 0.375 & 465 & 0.398 & 0.38 & 0.407 & 0.357 & 0.461 & 0.357 & 0.389 \\
\hline & D & 0.427 & 0.353 & 0.404 & 0.382 & 0.403 & 0.404 & 0.455 & 0.388 & 0.383 & 0.392 & 0.364 & 0.367 \\
\hline & $\mathrm{E}$ & 0.396 & 0.397 & 0.394 & 0.46 & 0.394 & 0.422 & 0.4 & 0.367 & 0.4 & 0.359 & 0.338 & 0.446 \\
\hline & $\mathrm{F}$ & 0.418 & 0.352 & 0.401 & 0.422 & 0.379 & 0.408 & 0.4 & 0.436 & 0.385 & 0.33 & 0.319 & 0.406 \\
\hline & G & 0.398 & 0.326 & 0.378 & 0.416 & 0.399 & 0.385 & 0.384 & 0.916 & 0.375 & 0.33 & 0.415 & 0.484 \\
\hline & $\mathrm{H}$ & 0.348 & 1.027 & 0.296 & 0.247 & 0.28 & 0.297 & 0.275 & 0.306 & 0.248 & 0.264 & 0.293 & 0.242 \\
\hline \multirow{9}{*}{$\begin{array}{c}\text { Plate } \\
4\end{array}$} & C4 & 1 & 2 & 3 & 4 & 5 & 6 & 7 & 8 & 9 & 10 & 11 & 12 \\
\hline & A & 0.301 & 0.265 & 0.324 & 0.371 & 0.435 & 0.44 & 0.387 & 0.402 & 0.387 & 0.356 & 0.365 & 0.397 \\
\hline & B & 0.442 & 0.38 & 0.416 & 0.328 & 0.538 & 0.406 & 0.377 & 0.361 & 0.348 & 0.384 & 0.364 & 0.912 \\
\hline & C & 0.403 & 0.391 & 0.407 & 0.451 & 0.359 & 353 & 0.438 & 0.555 & 0.401 & 0.411 & 0.394 & 602 \\
\hline & D & 0.584 & 0.389 & 0.423 & 0.354 & 0.386 & 1.339 & 0.42 & 0.375 & 0.497 & 0.375 & 0.377 & 356 \\
\hline & $\mathrm{E}$ & 0.425 & 0.385 & 0.395 & 0.407 & 0.413 & 416 & 0.371 & 0.363 & 0.418 & 0.424 & 0.304 & 412 \\
\hline & $\mathrm{F}$ & 0.433 & 0.387 & 0.423 & 0.4 & 0.449 & 0.371 & 0.361 & 0.343 & 0.372 & 0.349 & 0.346 & 377 \\
\hline & G & 0.383 & 0.332 & 0.28 & 0.383 & 0.378 & 0.333 & 0.379 & 0.381 & 0.321 & 0.341 & 0.325 & 425 \\
\hline & $\mathrm{H}$ & 0.373 & 0.315 & 0.373 & 0.37 & 0.403 & 0.364 & 0.385 & 0.843 & 0.406 & 0.359 & 0.322 & 406 \\
\hline
\end{tabular}

Bold font represents wells with high titers. The titers of red boxes are as follows: Plate 1, C1E4 (1.043), C1G3 (1.197), C1H12 (0.833); Plate 2, C2G11 (1.137), C2H2 (0.984); Plate 3, C3B11 (0.934), C3G8 (0.916), C3H2 (1.027); Plate 4, C4B12 (0.912), C4D6 (1.339), C4H8 (0.843).

\subsection{Monoclonal Cell Selection and Culture}

After dispensing the 11 selected cells into a 96-well plate, serial dilutions were performed. For selective culture, HAT medium was dispensed at $200 \mu \mathrm{L} /$ well and cultured at $37^{\circ} \mathrm{C}$ in a $\mathrm{CO}_{2}$ incubator. New HAT medium $(100 \mu \mathrm{L} /$ well $)$ was added once every 2 days. Finally, seven candidate clones were selected by indirect ELISA (Table 4).

\subsection{Ascites Production and Mass Production of Monoclonal Antibodies}

The hybridomas selected for mass production of monoclonal antibodies were injected into the abdominal cavity of mice. When the mouse abdominal cavity swelled after 7 to $10 \mathrm{~d}$, ascites were collected and centrifuged at $3243 \times g, 25{ }^{\circ} \mathrm{C}$ for $5 \mathrm{~min}$. The supernatant was then collected and stored at $-40{ }^{\circ} \mathrm{C}$. 
Table 4. Results of the half-pair test.

\begin{tabular}{llllllll}
\hline G/C & C1G3 & C2G11 & C2H2 & C3B11 & C3H2 & C4B12 & C4D6 \\
\hline C1G3 & - & $1+$ & $3+$ & $3+$ & $2+$ & - & - \\
C2G11 & $1+$ & - & - & $2+$ & $1+$ & $1+$ & $1+$ \\
C2H2 & - & - & - & $3+$ & - & $2+$ & $3+$ \\
C3B11 & $2+$ & $1+$ & - & $3+$ & - & $1+$ & $2+$ \\
C3H2 & $2+$ & - & - & $2+$ & - & $1+$ & $1+$ \\
C4B12 & - & $1+$ & $3+$ & $3+$ & $2+$ & - & - \\
C4D6 & - & $1+$ & $2+$ & $1+$ & $1+$ & - & - \\
\hline
\end{tabular}

Specific sensitivity: $3+$ (strong positive); $2+$ (weak positive); $1+$ (positive); - (negative).

\subsection{Purification of Monoclonal Antibodies}

In order to purify monoclonal antibodies, ascites stored at $-40{ }^{\circ} \mathrm{C}$ were dissolved at room temperature, diluted with PBS ( $\mathrm{pH}$ 7.4) at a ratio of 1:3, and filtered through a $0.22-\mu \mathrm{m}$ membrane filter. The proteins in this dialysate were subjected to $A+G$ affinity chromatography and sufficiently washed with PBS ( $\mathrm{pH}$ 7.4) for at least $30 \mathrm{~min}$ to remove nonspecific substances. The antibodies bound to the column were eluted with PBS (pH 3.2). At this time, $1 \mathrm{M}$ neutralization buffer solution consisting of $1 \mathrm{M}$ Tris-base ( $\mathrm{pH}$ 9.0), which was $1 / 100$ of the elution volume, was added to correct the elution. The elution was dialyzed for $24 \mathrm{~h}$ with PBS ( $\mathrm{pH} 7.4$ ) to remove salts.

\subsection{Preparation of Gold Nanoparticles and Antibody Conjugates}

Gold conjugate was used to label antigen-antibody binding in an easy-to-understand manner. First, a flask was filled with $1 \mathrm{~L}$ of tertiary distilled water and heated on a stirrer. When the distilled water began to boil at $100{ }^{\circ} \mathrm{C}$, the mixture was treated with $100 \mathrm{~mL}$ of $10 \%$ trisodium citrate and $100 \mathrm{~mL}$ of $0.1 \%$ gold chloride and stirred with a magnetic bar. When the yellow solution turned purple, it was heated for an additional $10 \mathrm{~min}$, transferred to a 1-L glass bottle, and cooled slowly. The gold nanoparticle solution was titrated at $\mathrm{pH} 7.5$, using $1 \mathrm{M} \mathrm{K}_{2} \mathrm{CO}_{3}$, and conjugated with the antibodies based on the size of OD 2.0 at $540 \mathrm{~nm}$ absorbance. After stirring at $25^{\circ} \mathrm{C}$ for $10 \mathrm{~min}$, blocking was performed by adding $0.25 \%$ casein.

\subsection{Rapid Diagnosis Kit Production and Components}

A half-pair test was performed to examine reactivity between antibodies (Table 4). The recombinant NT-proBNP antigen was diluted in a gold nanoparticle condensation solution and dispensed at a concentration of $10 \mathrm{ng} / \mathrm{mL}$ into a 96-well plate. Positive and negative strips were prepared, and the two control lines were treated with goat anti-mouse $\operatorname{IgG}(1 \mathrm{mg} / \mathrm{mL})$. The candidate clonal antibody was dispensed at $2 \mathrm{mg} / \mathrm{mL}$ in the positive strip test line. In contrast, $100 \mathrm{mM}$ phosphate buffer ( $\mathrm{pH}$ 7.4) was dispensed onto the negative strip test line to determine the presence or absence of false positives. Subsequently, antibodies with good sensitivity were selected using the half-pair test. Diagnostic kits were produced using candidate clonal antibodies to perform full-strip pair tests. A composition of the diagnostic kits used is shown in Figure 1. A test line and a control line were placed on a nitrocellulose membrane. Thereafter, $2 \mathrm{mg} / \mathrm{mL}$ antibody was dispensed onto the test line to capture the antigen, whereas $1 \mathrm{mg} / \mathrm{mL}$ goat anti-mouse $\mathrm{IgG}$ was dispensed onto the control line.

\subsection{Antigen-Antibody Reactivity Test}

The recombinant NT-proBNP antigen (HyTest, Turku, Finland) required for accurate antigen-antibody reactivity tests, as well as different concentrations of NT-proBNP plasma (ProMedex, Marlboro, NJ, USA) from four different patients, were purchased from the indicated companies (Table 5). For the test, $100 \mu \mathrm{L}$ of the sample was dispensed onto the sample pad, and the reaction was examined after approximately $10 \mathrm{~min}$. The control 
line was examined for all experiments. The appearance of a band on the test line was considered positive.

Table 5. NT-proBNP plasma specimens.

\begin{tabular}{lllll}
\hline Lane & Specimen & $\begin{array}{l}\text { Concentration } \\
(\mathbf{n g} / \mathbf{m L})\end{array}$ & Sex & Age (Years) \\
\hline$(1)$ & Normal serum & - & - & - \\
$(2)$ & Recombinant Antigen & 10 & - & - \\
$(3)$ & Commercial Antigen & 10 & - & - \\
$(4)$ & Patient's serum (1) & 35 & Female & 59 \\
$(5)$ & Patient's serum (2) & 25 & Female & 93 \\
$(6)$ & Patient's serum (3) & 16 & Female & 86 \\
$(7)$ & Patient's serum (4) & 10 & Female & 91 \\
\hline
\end{tabular}

\subsection{Statistical Analysis}

Statistical analyses were performed using frequency analysis and graphing with MS Excel (Microsoft, Redmond, Washington, DC, USA) and SPSS Statistical Procedure for Windows (SPSS PASW Statistical 23.0; SPSS Inc., Chicago, IL, USA). Cohen's kappa statistic was used for agreement on the measurement category values.

\section{Results}

\subsection{NT-proBNP Gene Synthesis and Cloning}

A primer containing HindIII and XhoI restriction enzyme cleavage sites was designed, using NT-proBNP as a template, by Bioneer (Korea) and used in the PCR. An analysis of the amplified NT-proBNP product showed a band of approximately 228 bp on a $1.5 \%$ agarose gel (Figure 2). The identified band was extracted with the desired target inserts using a gel extraction kit and recombined using a TA-cloning kit. Following the transformation with E. coli $\mathrm{DH} 5 \alpha$, subcloning was performed using the $\mathrm{pET}-21 \mathrm{~b}$ expression vector to express the recombinant protein.

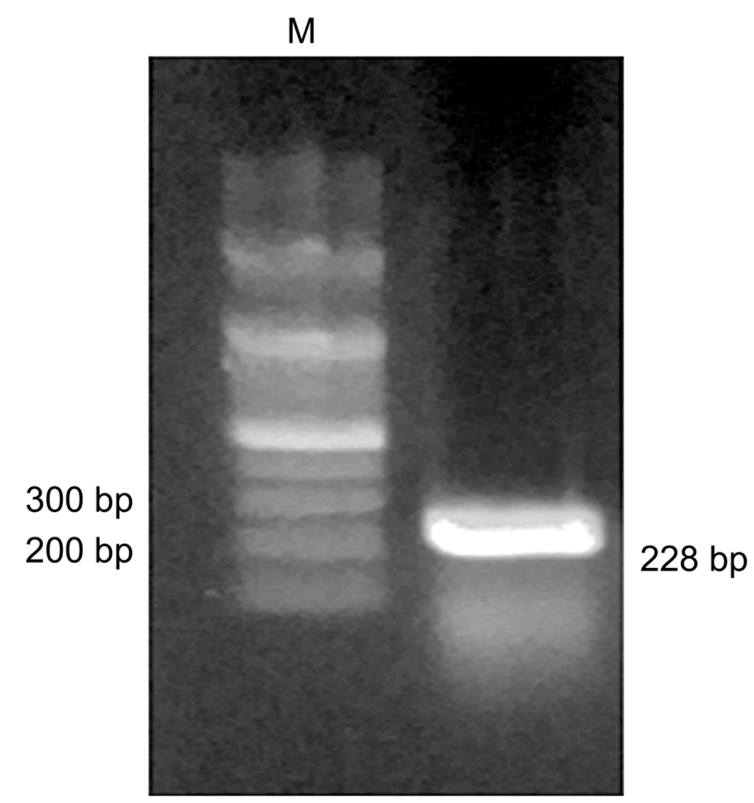

Figure 2. Agarose gel electrophoresis analysis of the NT-proBNP DNA fragment amplified via PCR. Lane M indicates the $100 \mathrm{bp}$ DNA ladder. Lane L contains the PCR products of NT-proBNP. The approximate size of the amplified DNA fragment was $228 \mathrm{bp}$. 


\subsection{Recombinant Protein Expression and Purification}

Proteins were extracted from transformed E. coli BL21 (DE3) and purified via Ni-NTA affinity chromatography. Analysis of the eluted protein via SDS-PAGE revealed a thick protein band of approximately $13 \mathrm{kDa}$ (Figure 3). The recombinant NT-proBNP protein was used as an antigen to produce monoclonal antibodies for immunization.

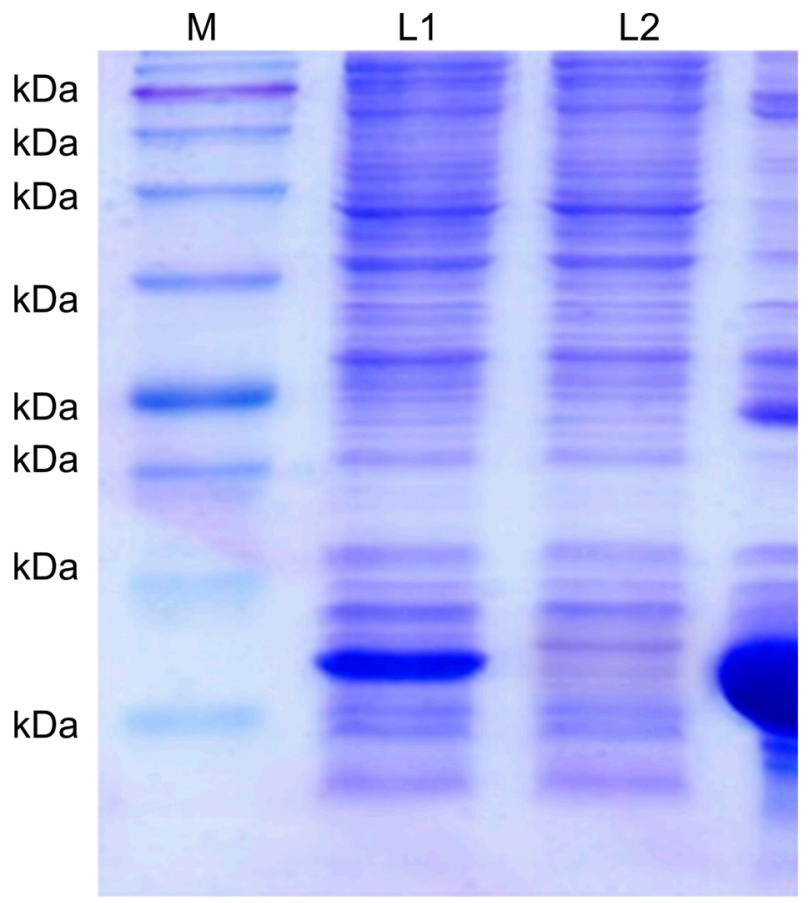

Figure 3. SDS-PAGE analysis of the NT-proBNP recombinant protein. M: protein marker (kDa); L1: supernatant (lysate); L2: filtrate; L3: elution.

\subsection{Immunization and Hybridoma Screening}

Hybridomas, produced by the fusion of lymph nodes from immunized mice with Sp2/O cells, were selectively cultured and screened via indirect ELISA (Table 3 ). After the screening, approximately 11 samples (C1E4, C1G3, C1H12, C2G11, C2H2, C3B11, C3G8, $\mathrm{C} 3 \mathrm{H} 2, \mathrm{C} 4 \mathrm{~B} 12, \mathrm{C} 4 \mathrm{D} 6$, and $\mathrm{C} 4 \mathrm{H} 8$ ) showed high absorbance. Seven monoclonal candidates were established by serially diluting the selected clones several times (Table 4, Figure 4).

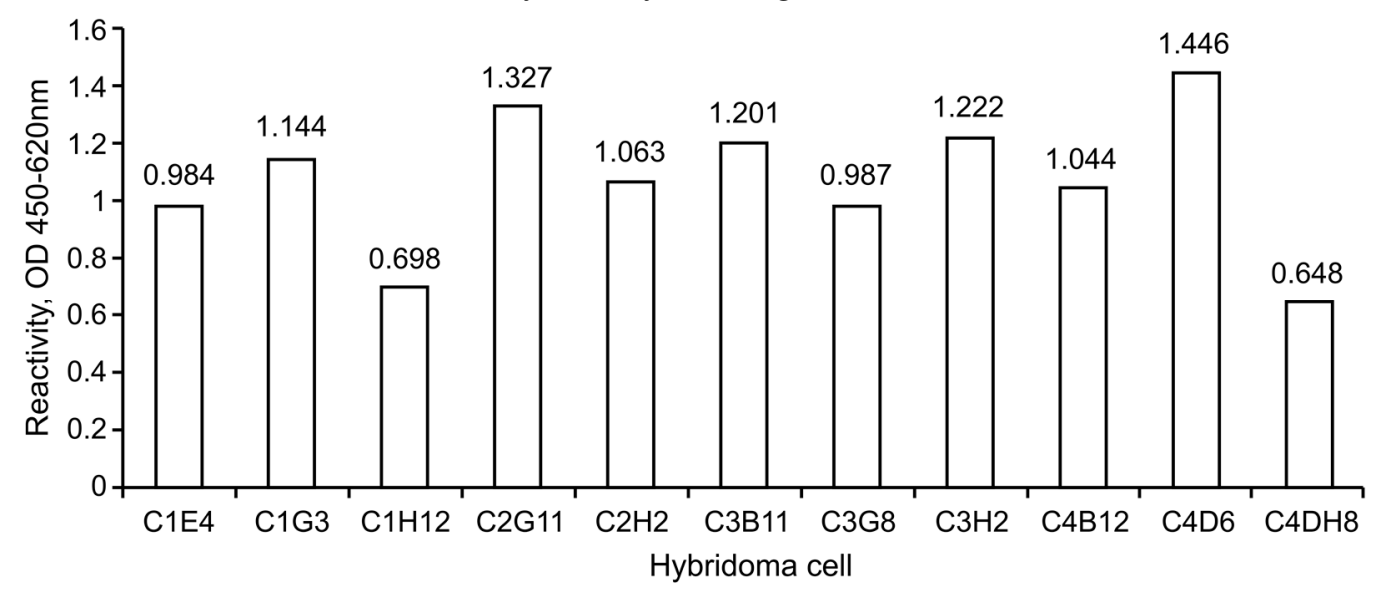

Figure 4. Serial dilution for monoclonal antibody screening. Final clones were selected through serial dilution: C1G3 (1.144), C2G11 (1.327), C2H2 (1.063), C3B11 (1.201), C3H2 (1.222), C4B12 (1.044), and C4D6 (1.446). 


\subsection{Mass Production and Purification of Monoclonal Antibodies}

To obtain a large number of ascites and purify the antibodies, ascites were collected by injecting fused cells into the abdominal cavity of the mouse. Protein $A+G$ affinity chromatography was used to bind ascites to the resin. Following adequate washing with PBS (pH 7.4), nonspecific substances were removed, and the antibody was eluted based on the difference in $\mathrm{pH}$.

\subsection{Monoclonal Antibody Pair Test}

Half-pair tests were performed by selecting seven candidate clonal antibodies. Clonal antibodies were dispensed on the membrane at a concentration of $2 \mathrm{mg} / \mathrm{mL}$, and gold nanoparticle conjugate solutions were prepared. To select gold nanoparticle-conjugated antibodies and capture antibodies, approximately 49 cases were substituted. As a result of the half-pair test, eight highly sensitive pairs were selected, and the kit was assembled and tested to accurately diagnose its reactivity. Seven kits were prepared per pair test, and serum (negative plasma) of healthy individuals was selected as a control to determine false positives. To examine the reactivity of the antigen, the recombinant NT-proBNP antigen developed in this study and recombinant NT-proBNP antigen purchased from HyTest were diluted and dispensed at $10 \mathrm{ng} / \mathrm{mL}$. The NT-proBNP serum (plasma) purchased from ProMedex $(100 \mu \mathrm{L}$ each) was dispensed in the order of high to low concentrations $(35,25$, 16 , and $10 \mathrm{ng} / \mathrm{mL}$ ). The pair test indicated that, among the eight pairs of tests, the best sensitivity was shown by the H:C3B11(Capture)/C4B12(Gold) pair (Figure 5).
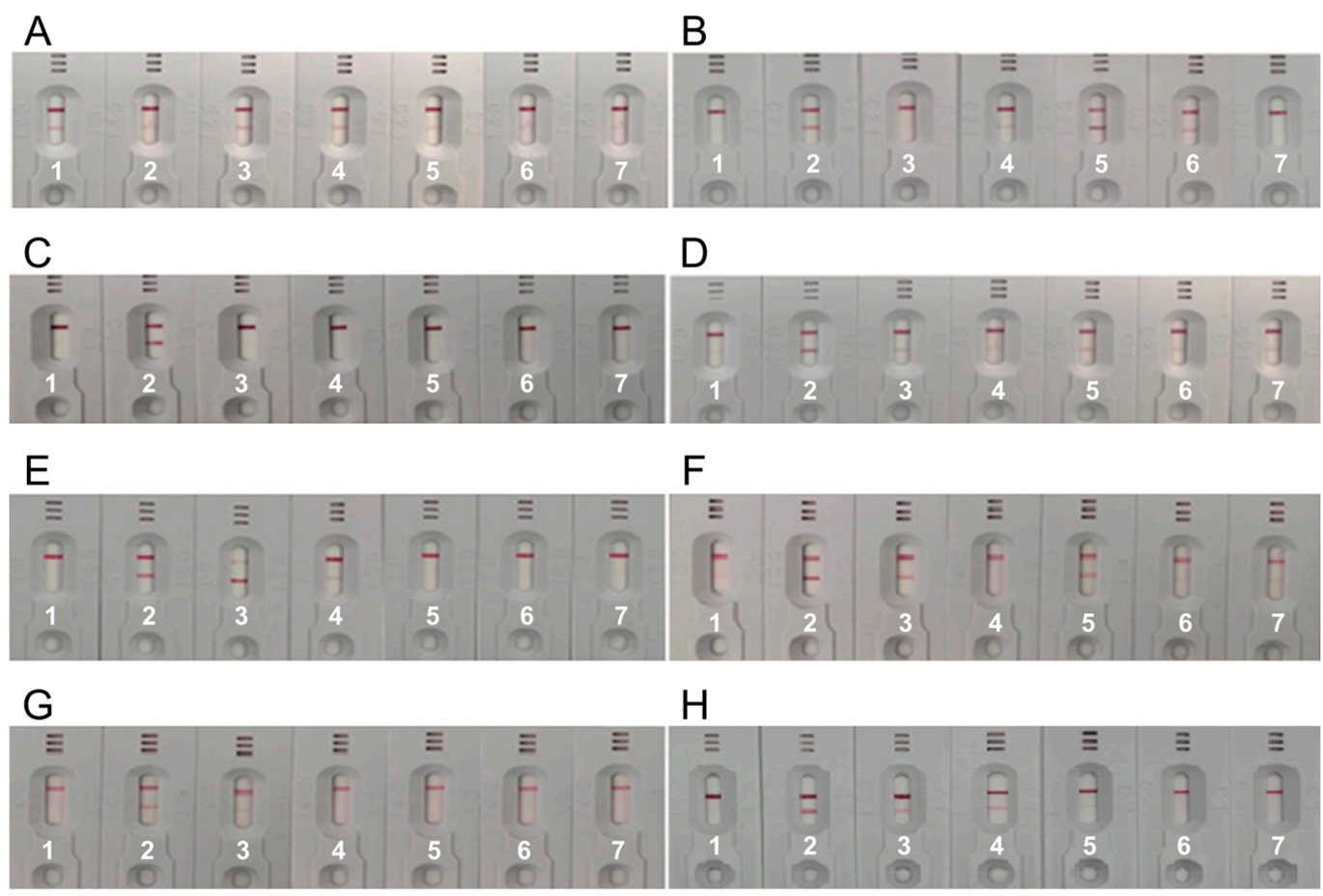

Figure 5. Specificity of the NT-proBNP rapid diagnosis kit. Letters " $\mathrm{C}$ " and " $\mathrm{G}$ " stand for Capture and Gold, respectively. (A) $\mathrm{C} 2 \mathrm{H} 2(\mathrm{C}) / \mathrm{C} 1 \mathrm{G} 3(\mathrm{G}) ;$ (B) C3B11(C)/C1G3(G); (C) C1G3(C)/C2H2(G); (D) C3B11(C)/C2H2(G); (E) C4D6(C)/C2H2(G); (F) C3B11(C)/C3B11(G); (G) C2H2(C)/C4B12(G); (H) C3B11(C)/C4B12(G).

\section{Discussion}

Globally, the HF rate has been increasing exponentially with the aging population. Increased life expectancy in the United States has resulted in one in three individuals suffering from some form of heart disease [18]. Heart failure, a progressive disease, is the most common cause of death due to cardiovascular ailments. Its prevalence is increasing along with the number of patients and elderly individuals with chronic heart diseases due 
to the availability of various treatment technologies. Thus, HF is considered an important disease in terms of socioeconomics $[19,20]$.

Echocardiography is considered the gold standard for diagnosing HF, but its efficacy is compromised in patients with chronic lung disease and obese patients with respiratory failure [21,22]. Although various methods enabling the early detection of $\mathrm{HF}$ are available, these traditional methods do not ensure efficacy, accuracy, timeliness and cost-effectiveness of clinical decisions, prognoses, or treatments. In fact, delays in HF diagnosis can lead to inadequate treatment, increased medical expenses, extended hospital stays, and increased emergency room visits [23,24].

Current biomarkers for diagnosing HF include CRP and IL-6 inflammatory biomarkers, $\mathrm{HF}$ myocyte injury biomarkers $\mathrm{CTnI}$ and $\mathrm{CK}-\mathrm{MB}$, and HF myocyte stress biomarkers such as BNP and ST2. Among them, the specificity of BNP and ST2 is relatively higher than that of other markers. In particular, BNP is known to be a strong prognostic predictor for all causes of death in patients with HF and is released from the heart in response to hypertrophy, mechanical stress, increased myocardial tone under conditions of oxidative stress and increased intravascular volume. Therefore, BNP is routinely used to diagnose and monitor $\mathrm{HF}$ and is an important prognostic indicator of mortality, particularly in patients with HF $[25,26]$. Recently, NT-proBNP has been used as a routine laboratory test for diagnosing $\mathrm{HF}$ and has already proven to be useful in clinical tests for the differential diagnosis of acute respiratory distress, HF diagnosis and prognosis in several studies [27]. In this study, based on the NT-proBNP test system, a new NT-proBNP amino acid sequence was selected based on the NCBI Human proBNP database to develop an antibody for application in a rapid diagnostic kit in a clinical setting. The target gene was then amplified through PCR. In addition, a high-purity NT-proBNP recombinant antigen was obtained by subcloning, using a vector, and purifying the target protein. This antigen was used for immunization. A large number of monoclonal antibodies was produced through fusion cell selection and purification and was applied to an optimal rapid diagnostic kit to confirm reactivity with a commercially available standard antigen, that is, sensitivity and specificity. Thus, a new recombinant protein antigen based on human NT-proBNP was developed, and a large number of monoclonal antibodies was obtained using this antigen. In addition, the analysis of antigen-antibody reactivity by applying it to a gold conjugate-based optimal diagnostic kit revealed superior sensitivity and specificity. We plan on applying to related organizations for permission to commercialize once we have finished developing a reader machine with high interoperability using the diagnostic kit which applied this antibody protein and conduct additional clinical trials.

\section{Conclusions}

In conclusion, the field application of the CHF rapid diagnosis kit constructed using the recombinant NT-proBNP antigen developed in this study may reduce costs and replace methods requiring expensive equipment and expertise to diagnose related diseases. Thus, it may substantially contribute to the prognosis and treatment of heart diseases.

Author Contributions: Y.-K.L. \& D.-O.C. contributed equally to this work. Conceptualization, G.-Y.K. and D.-O.C.; methodology, Y.-K.L.; software, Y.-K.L.; validation, Y.-K.L., D.-O.C. and G.-Y.K.; formal analysis, Y.-K.L. and D.-O.C.; investigation, Y.-K.L.; resources, G.-Y.K.; data curation, Y.-K.L. and D.-O.C.; writing-original draft preparation, D.-O.C.; writing-review and editing, Y.-K.L. and D.-O.C.; visualization, D.-O.C.; supervision, G.-Y.K.; project administration, G.-Y.K.; funding acquisition, G.-Y.K. All authors have read and agreed to the published version of the manuscript.

Funding: This research received no external funding.

Institutional Review Board Statement: This study was approved by the Institutional Animal Care and Use Review Committee of Bore Da BioTECH (protocol code BDIACUC20180221 and date of approval: 21 February 2018).

Informed Consent Statement: Not applicable. 
Data Availability Statement: The datasets used and/or analysed during the current study are available from the corresponding author on reasonable request.

Acknowledgments: This research was supported by intramural research funds from the dankook University Research in korea (R202100641).

Conflicts of Interest: The authors declare no conflict of interest.

\section{References}

1. Dunlay, S.M.; Shah, N.D.; Shi, Q.; Morlan, B.; VanHouten, H.; Long, K.H.; Roger, V.L. Lifetime Costs of Medical Care After Heart Failure Diagnosis. Circ. Cardiovasc. Qual. Outcomes 2011, 4, 68-75. [CrossRef] [PubMed]

2. Cheng, S.; Vasan, R.S. Advances in the Epidemiology of Heart Failure and Left Ventricular Remodeling. Circulation 2011, 124, e516-e519. [CrossRef]

3. Sardu, C.; Marfella, R.; Santamaria, M.; Papini, S.; Parisi, Q.; Sacra, C.; Colaprete, D.; Paolisso, G.; Rizzo, M.R.; Barbieri, M. Stretch, Injury and Inflammation Markers Evaluation to Predict Clinical Outcomes After Implantable Cardioverter Defibrillator Therapy in Heart Failure Patients With Metabolic Syndrome. Front. Physiol. 2018, 9, 758. [CrossRef] [PubMed]

4. Hall, C. NT-ProBNP: The Mechanism Behind the Marker. J. Card. Fail. 2005, 11, S81-S83. [CrossRef]

5. Lu, Z.; Wang, B.; Wang, Y.; Qian, X.; Zheng, W.; Wei, M. Relationship between CCR and NT-proBNP in Chinese HF Patients, and Their Correlations with Severity of HF. BioMed Res. Int. 2014, 2014. [CrossRef] [PubMed]

6. Grewal, J.; McKelvie, R.; Lonn, E.; Tait, P.; Carlsson, J.; Gianni, M.; Jarnert, C.; Persson, H. BNP and NT-proBNP predict echocardiographic severity of diastolic dysfunction. Eur. J. Heart Fail. 2008, 10, 252-259. [CrossRef]

7. Hall, C. Essential biochemistry and physiology of (NT-pro)BNP. Eur. J. Heart Fail. 2004, 6, 257-260. [CrossRef]

8. Sarangadharan, I.; Huang, S.-W.; Kuo, W.-C.; Chen, P.-H.; Wang, Y.-L. Rapid detection of NT-proBNP from whole blood using FET based biosensors for homecare. Sens. Actuators B Chem. 2019, 285, 209-215. [CrossRef]

9. Pfister, R.; Scholz, M.; Wielckens, K.; Erdmann, E.; Schneider, C. Use of NT-proBNP in routine testing and comparison to BNP. Eur. J. Heart Fail. 2004, 6, 289-293. [CrossRef]

10. Salah, K.; Stienen, S.; Pinto, Y.M.; Eurlings, L.W.; Metra, M.; Bayes-Genis, A.; Verdiani, V.; Tijssen, J.G.P.; Kok, W.E. Prognosis and NT-proBNP in heart failure patients with preserved versus reduced ejection fraction. Heart 2019, 105, 1182-1189. [CrossRef]

11. Sardu, C.; Paolisso, P.; Sacra, C.; Santamaria, M.; De Lucia, C.; Ruocco, A.; Mauro, C.; Paolisso, G.; Rizzo, M.R.; Barbieri, M.; et al. Cardiac resynchronization therapy with a defibrillator (CRTd) in failing heart patients with type 2 diabetes mellitus and treated by glucagon-like peptide 1 receptor agonists (GLP-1 RA) therapy vs. conventional hypoglycemic drugs: Arrhythmic burden, hospitalizations for heart failure, and CRTd responders rate. Cardiovasc. Diabetol. 2018, 17, 137. [CrossRef] [PubMed]

12. Sardu, C.; Paolisso, P.; Ducceschi, V.; Santamaria, M.; Sacra, C.; Massetti, M.; Ruocco, A.; Marfella, R. Cardiac resynchronization therapy and its effects in patients with type 2 DIAbetes mellitus OPTimized in automatic vs. echo guided approach. Data from the DIA-OPTA investigators. Cardiovasc. Diabetol. 2020, 19. [CrossRef]

13. Dębska-Kozłowska, A.; Książczyk, M.; Warchol, I.; Lubinski, A. Clinical Usefulness of N-terminal Prohormone of Brain Natriuretic Peptide and High Sensitivity Troponin T in Patients with Heart Failure Undergoing Cardiac Resynchronization Therapy. Curr. Pharm. Des. 2019, 25, 1671-1678. [CrossRef] [PubMed]

14. Vasheghani-Farahani, A.; Sherafati, A. Usefulness of Biomarkers for Predicting Response to Cardiac Resynchronization Therapy. Curr. Cardiol. Rev. 2020, 16, 132-140. [CrossRef]

15. San-Miguel, T.; Pérez-Bermúdez, P.; Gavidia, I. Production of soluble eukaryotic recombinant proteins in E. coli is favoured in early log-phase cultures induced at low temperature. SpringerPlus 2013, 2. [CrossRef] [PubMed]

16. Bornhorst, J.A.; Falke, J.J. [16] Purification of proteins using polyhistidine affinity tags. Methods Enzymol. 2000, 326, 245-254. [CrossRef] [PubMed]

17. Laemmli, U.K. Cleavage of structural proteins during the assembly of the head of bacteriophage T4. Nature 1970, 227, 680-685. [CrossRef]

18. Gopal, D.J.; Iqbal, M.N.; Maisel, A. Updating the Role of Natriuretic Peptide Levels in Cardiovascular Disease. Postgrad. Med. 2011, 123, 102-113. [CrossRef]

19. Anguita, M.; Montes, P.; Jordán, A.; Casares, G.; Gómez, I.; Recio, J.; Martínez, Á.; Zumalde, J.; Povar, J.; Ridocci, R.; et al. Utility of NT-proBNP for diagnosing heart failure in a heterogeneous population of patients with dyspnea. Spanish multicenter study. Rev. Esp. Cardiol. 2006, 59, 465-472. [CrossRef]

20. Hobbs, F.D.R.; Davis, R.C.; Roalfe, A.K.; Hare, R.; Davies, M.K.; Kenkre, J.E. Reliability of N-terminal pro-brain natriuretic peptide assay in diagnosis of heart failure: Cohort study in representative and high risk community populations. BMJ 2002, $324,1498$. [CrossRef]

21. Farnsworth, C.W.; Bailey, A.L.; Jaffe, A.S.; Scott, M.G. Diagnostic concordance between NT-proBNP and BNP for suspected heart failure. Clin. Biochem. 2018, 59, 50-55. [CrossRef]

22. Masson, S.; Latini, R.; Anand, I.S.; Vago, T.; Angelici, L.; Barlera, S.; Missov, E.D.; Clerico, A.; Tognoni, G.; Cohn, J.N. Direct Comparison of B-Type Natriuretic Peptide (BNP) and Amino-Terminal proBNP in a Large Population of Patients with Chronic and Symptomatic Heart Failure: The Valsartan Heart Failure (Val-HeFT) Data. Clin. Chem. 2006, 52, 1528-1538. [CrossRef] [PubMed] 
23. Alawieh, H.; El Chemaly, T.; Alam, S.; Khraiche, M. Towards Point-of-Care Heart Failure Diagnostic Platforms: BNP and NT-proBNP Biosensors. Sensors 2019, 19, 5003. [CrossRef] [PubMed]

24. Soleh, M.T.; Foo, J.Y.Y.; Bailey, U.-M.; Tan, N.Y.; Wan, Y.; Cooper-White, J.; Schulz, B.L.; Punyadeera, C. A rapid and cost-effective method of producing recombinant proBNP and NT-proBNP variants in Escherichia coli for immunoassay of heart failure. Biotechnol. Lett. 2014, 36, 133-140. [CrossRef] [PubMed]

25. Kim, Y.S.; Karisa, N.; Jeon, W.Y.; Lee, H.; Kim, Y.-C.; Ahn, J. High-level production of N-terminal pro-brain natriuretic peptide, as a calibrant of heart failure diagnosis, in Escherichia coli. Appl. Microbiol. Biotechnol. 2019, 103, 4779-4788. [CrossRef]

26. Braunwald, E. Biomarkers in Heart Failure. N. Engl. J. Med. 2008, 358, 2148-2159. [CrossRef] [PubMed]

27. Usuku, H.; Nakayama, M.; Sumida, H.; Yamamuro, M.; Izumiya, Y.; Suzuki, S.; Kusuhara, K.; Ueno, H.; Sugiyama, S.; Yoshimura, M.; et al. Pump failure death and sudden cardiac death in patients with cardiac dysfunction: A search for prognostic predictive factors-A long-term follow-up study. J. Cardiol. 2010, 55, 55-64. [CrossRef] [PubMed] 